\title{
Absence of Seroconversion in a PCR-Positive Person 18 Months after Transfusion of HIV-infected Blood
}

\author{
Dolores Vaira, Ch. François-Gérard, B. Rentier, D. Sondag-Thull
}

Reference Laboratory for AIDS diagnosis, Blood Transfusion Center, University of Liège, Belgium

Several cases of HIV 1 transmission by seronegative blood collected from HIV-infected donors have already been reported [1]. The present case has been followed up for more than 1 year. 18 months after transfusion, the recipient of the infected blood has not yet seroconverted even though the provirus has repeatedly been proved to be present in peripheral white blood cells by PCR.

The donor, a 25-year-old man was a regular blood donor who has been tested for HIV 1 antibodies and found to be negative till September 1987. Three months later, in December 1987, this donor had seroconverted. Much later, we heard that homosexual contacts, dated July 1987, were most probably at the origin of the HIV 1 contamination. In December 1987, no antigen could be detected in his serum by using the EIA neutralization test from Abbott. 7 months after contamination, in January 1988, the $\mathrm{T}_{4} / \mathrm{T}_{8}$ ratio of the donor's lymphocytes was as low as 0.28 with a total $\mathrm{T}_{4}$ cell count of $657 \mathrm{c} / \mathrm{mm}^{3}$. Further investigation of the donor's immune function showed that lymphoblastic stimulation was lowered with PHA and PKW, whereas it was in the normal range with $\mathrm{OKT}_{3}$ as mitogen.

Because the donor was thought to be infectious at least since September, we searched for the recipients of his blood. The red cells were the only blood fraction that had really been transfused. The recipient was a 92-year old woman whose anemia due to Hypersplenism required a blood transfusion in October 1987. Her HIV 1 serological data and immunological parameters have been determined every 2 months, up to 18 months after the contaminant transfusion. The presence of proviral HIV 1 was also searched for by the polymerase chain reaction (PCR) in peripheral blood mononuclear cells. The PCR was performed according to the procedure described previously [2], by using primers $\mathrm{SKO}_{1}, \mathrm{SKO}_{2}$ choosen in the gag gene of HIV 1 .

Serological and biological data were markedly reproducible and can be summarized as follows: neither HIV 1 antibody nor antigen could ever be detected. As far as 18 months after transfusion, the recipient still remains seronegative although HIV 1 viral genome was found in her lymphocytes. The unbalanced $\mathrm{T}_{4}$ and $\mathrm{T}_{8}$ lymphocyte subsets, mainly due to an increase of $\mathrm{T}_{8}$, gives an $\mathrm{H} / \mathrm{S}$ ratio (0.82) lower than the normal range. Moreover, there are very few B lymphocytes (1\%) and we do not know to what extent this correlates or not to the lack of seroconversion to HIV. The recipient does not present any clinical symptoms but those normally due to old age.

HIV transmission by blood transfusion is an event the probability of which is small but not nil [3]. The observation we decribe here results from the conjunction of issues that should not have occurred. The first failure is the non-exclusion by the physician from the Blood Center, or the non-self-deferal of the blood donor although he was likely to know that his behavior was risky. The second one is the inability of current EIA screening methods to detect infectious persons during the serologically 'silent' phase. In order to reduce the risk during this phase of HIV infection, and provided it could be adapted for large scale screening and reliable results, PCR should be recommended as screening method of blood donors. However, one can question the real significance and predictive value of PCR-posi-tive results among individuals who have no or nondetect-able HIV antibodies.

\section{References}

1 Ward, J.W.; Holmberg, S.D.; Allen, J.R., et al: Transmission of human immunodeficiency virus (HIV) by blood transfusion screened as negative for HIV antibody. New Engl. J. Med. 318: 373-378 (1988).

2 Ou, C. Y.; Kwok, S. W., et al: DNA amplification for direct detection of HIV-1 in DNA of peripheral blood mononuclear cells. Science 239: 295-299 (1988).

3 Peterman,T.A.; Lui, K.J.; Lawrence, D. N.; Allen, J. R.: Estimating the risks of transfusion associated acquired immune deficiency syndrome and human immunodeficiency virus infection. Transfusion 27: 371-376 (1987). 